\title{
Saubere Ablage der Spitze eines Katheterbeutels
}

Es ist ein alltägliches Problem in Klinik und Praxis: Wohin mit der Schlauchspitze des Katheterbeutels beim Wechsel eines transurethralen Blasenkatheters, Blasenfistelkatheters oder Nephrostomiekatheters? Unser folgender Tipp schafft Abhilfe.

Wird die Spitze des Katheterbeutels frei abgelegt, ist sie nicht mehr steril - häufig muss dann ein neuer Beutel verwendet werden und unnötige Kosten sind die Folge. Hier hat sich ein einfacher Trick bewährt: Die Spitze des Katheters wird mit dem sterilen Handschuh einer Hand angefasst und der Handschuh über die Katheterbeutelspitze einstülpend ausgezogen. So kommt die sterile Seite des Handschuhs nach innen und umhüllt die Katheterbeutelspitze. Der Beutel kann anschließend mit seinem Schlauch bis zum erneuten Anschluss an den gewechselten Katheter problemlosabgelegtwerden(○ Abb. 1).

Dr. Andreas Wiedemann, Witten

Korrespondenz:

Dr. Andreas Wiedemann

Evangelisches Krankenhaus

im Diakoniewerk Ruhr gGmbH

Lehrstuhl für Geriatrie

der Universität Witten/Herdecke

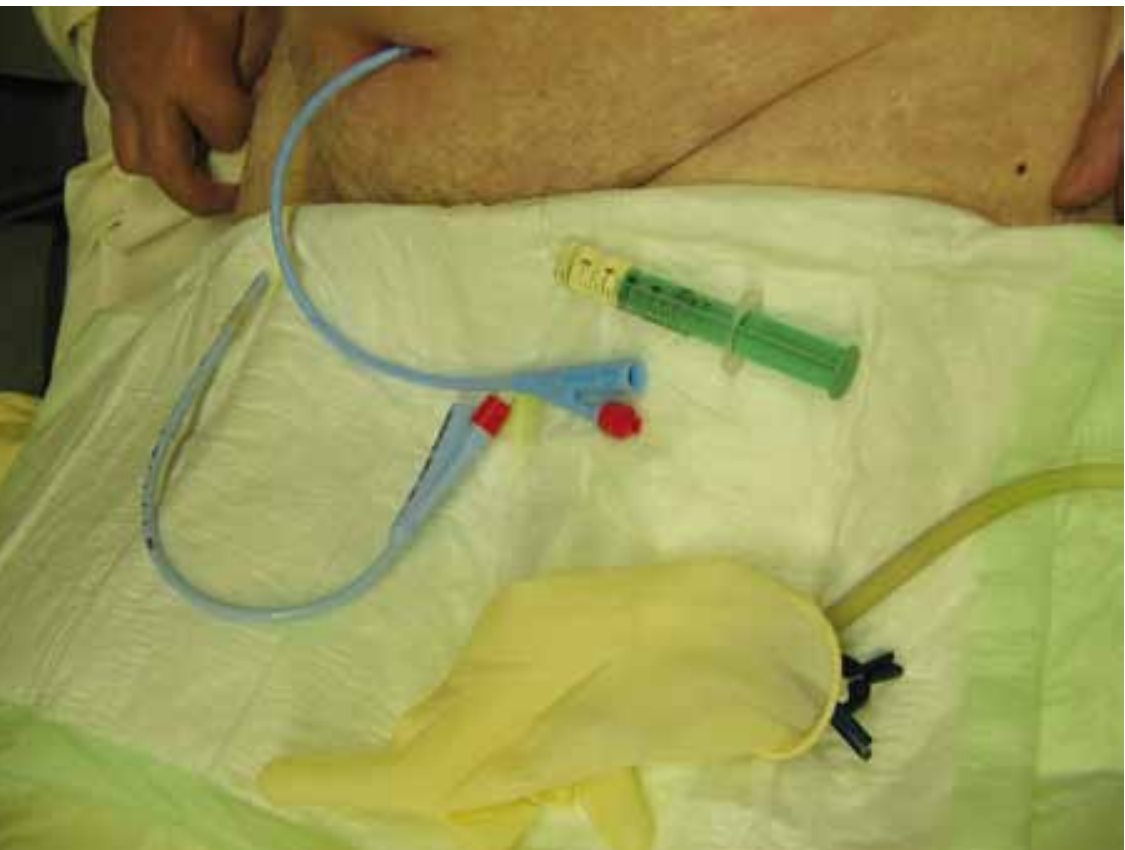

Abb.1 Alter und frisch gewechselter Blasenfistelkatheter. Der Beutelschlauch wurde in einen umgestülpten sterilen Handschuh eingeschlagen und so sauber abgelegt.

Pferdebachstr. 27

58455 Witten

Tel. 02302/175-2521

Fax. 02302/175-2075

awiedemann@diakonie-ruhr.de 